\title{
Outcomes of perioperative management in Jehovah's Witness patients undergoing surgeries with a risk of bleeding: a retrospective, single-center, observational study
}

\author{
Keum Young So, Sang Hun Kim \\ Department of Anesthesiology and Pain Medicine, Chosun University Hospital, Chosun University School of Medicine, Gwangju, Korea
}

Received August 18, 2021

Revised August 24, 2021

Accepted August 24, 2021

Corresponding author

Sang Hun Kim

Department of Anesthesiology and

Pain Medicine, Chosun University

School of Medicine, 309 Pilmun-

daero, Dong-gu, Gwangju 61453,

Korea

Tel: + 82-62-220-3223

Fax: + 82-62-223-2333

E-mail: ksh3223@chosun.ac.kr

ORCID:

https://orcid.org/0000-0003-3869-9470

\begin{abstract}
Jehovah's Witnesses (JWs) refuse allogeneic blood transfusions based on their religious beliefs. Anesthesiologists apply perioperative blood conservation strategies (BCSs) in patients who refuse allogeneic blood transfusions to prevent significant anemia or bleeding and avoid the need for transfusion. Therefore, we aimed to evaluate whether JW patients could safely undergo various surgeries that have a risk of bleeding without allogeneic transfusion, and compared their outcomes to those of patients allowing blood transfusion. We retrospectively collected data from 59 JW patients (JW group) and 362 non-JW patients (non-JW group) from January 1, 2010 to July 30, 2020. We defined surgeries with a risk of bleeding as open abdominal surgery, open gynecologic surgery, open hip surgery, open knee surgery, and spinal surgery. The primary endpoint was the mortality rate, and the secondary endpoints were the frequency of BCS application and postoperative morbidity. The mortality rate was $0 \%$ in the JW group and $3 \%$ in the nonJW group ( $p=0.370)$. The application of BCS was not significantly different between the groups $(p=0.071)$. Postoperative infection occurred in $8.4 \%$ of the non-JW group and in none in the JW group $(p=0.013)$; similarly, the incidence of disseminated intravascular coagulation was higher in the non-JW group (16\%) compared to the JW group $(3.4 \%)(\mathrm{p}=0.008)$. JW patients can safely undergo surgeries that have a risk of bleeding without significant mortality and perioperative complications, with comparable outcomes to patients who received blood transfusion.
\end{abstract}

Keywords: Blood conservation strategy; Jehovah's Witnesses; Morbidity; Mortality; Transfusion

\section{INTRODUCTION}

A Jehovah's Witness (JW) is a member of a Christian denomination that refuses blood transfusion. They believe that the Bible strictly prohibits the transfer of blood or blood products into a person's body. Therefore, they do not accept transfusions of whole blood (allogeneic and autologous) or its main components (red blood cells, plasma, white blood cells, and platelets) [1-4].

Perioperative blood conservation strategies (BCSs) can be adopted to reduce blood loss and minimize blood transfusion in patients undergoing surgery with a risk of bleeding and in patients who refuse blood transfusion [5,6]. Some JW patients allow the use of blood cell fractions, erythropoietin, acute normovolemic hemodilution, and intraoperative cell salvage, based on personal decision [1-4]. They may also al- 
low transfusion of their own blood by intraoperative cell salvage if the circuit system used remains continuous with their blood vessels at all times [1-4]. BCSs have been effective in the safe performance of bloodless surgeries in patients refusing transfusions, such as in JW patients [7-11]. However, there is still insufficient evidence on the safety of bloodless surgeries, especially in JWs, due to the small sample size of previous studies, including case reports.

Furthermore, there is still a risk for severe anemia requiring blood transfusion due to perioperative blood loss despite the application of BCSs [12]. Unlike in other patients who refuse transfusion, anesthesiologists often face an ethical, clinical, and medicolegal dilemma (whether or not to perform blood transfusion) in the management of perioperative bleeding and intrinsic anemia requiring transfusion in JW patients $[13,14]$. For this reason, some surgeons and hospitals often avoid accepting JW patients who need surgeries with a high risk of bleeding or complicated surgeries requiring blood transfusion.

In this study, we hypothesized that JW patients could safely undergo various surgeries without allogeneic blood transfusions. Through a review of electronic medical records, we analyzed the applied BCSs, perioperative hematologic changes, and morbidity and mortality in JW patients who underwent various surgeries with a risk of bleeding, and compared their outcomes to those of patients who received blood transfusion.

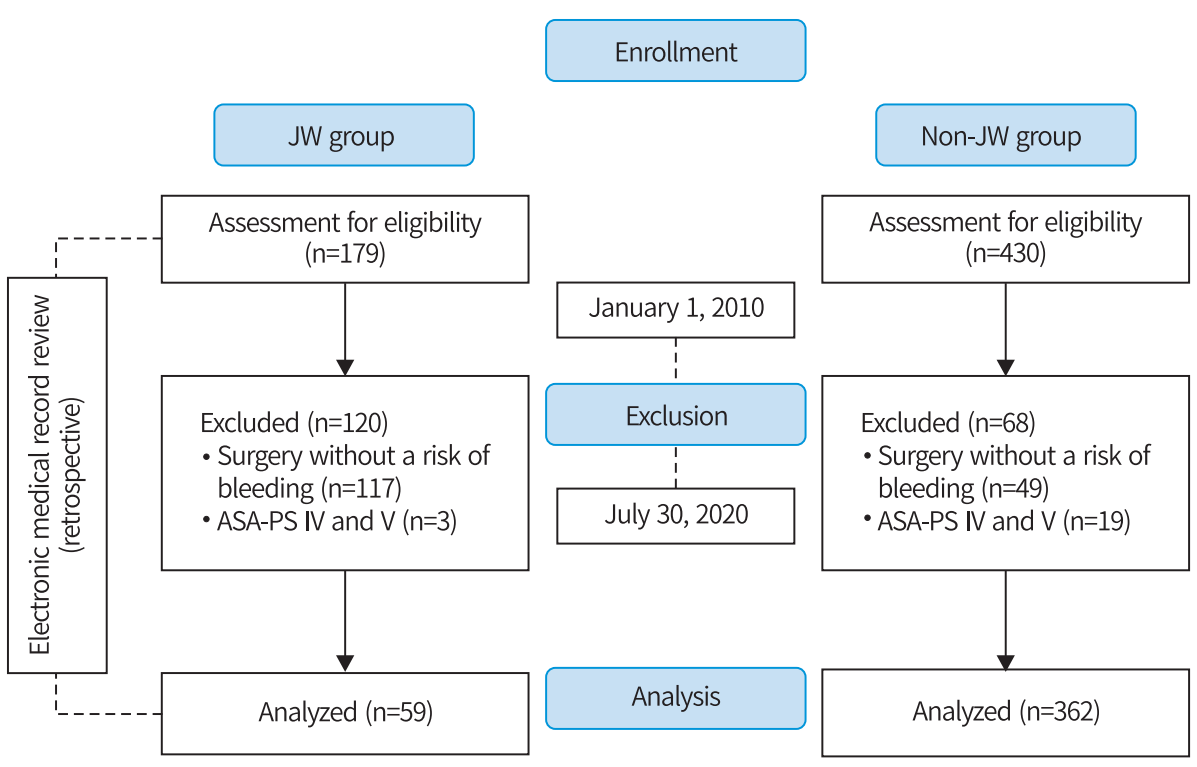

Fig. 1. Flowchart of patient inclusion. ASAPS: American Society of Anesthesiologists physical status, JW: Jehovah's Witness. 
same period (non-JW group, Fig. 1). We collected data from 430 non-JW patients, and finally reduced the non-JW group to include 362 patients who underwent surgeries with a risk of $\geq 500 \mathrm{~mL}$ of bleeding.

\section{Outcomes}

\section{Demographic data}

We assessed age, sex, weight, height, body mass index (BMI), ASA-PS, emergency status, classification of surgery, anesthesia duration, hospital stay duration, perioperative input (crystalloid and colloid), and blood loss.

\section{Perioperative BCS}

We assessed the use of perioperative antifibrinolytics, iron preparations, other systemic hemostatics, and cell salvage. Moreover, we assessed the anesthesia method, perioperative incidence of hypothermia, and intraoperative methods applied to prevent hypothermia. Hypothermia was defined as a body temperature of $\leq 36.0^{\circ} \mathrm{C}$.

\section{Perioperative transfusions}

We assessed the use of packed red blood cells, platelets, fresh frozen plasma, albumin, cryoprecipitate, and blood cell salvage.

\section{Mortality, morbidity, and other complications}

We assessed the incidences of death, infection, and disseminated intravascular coagulation (DIC) that occurred during hospitalization. Postoperative infection was defined as surgical wound infection or systemic infection, septicemia, peritonitis, and other infectious complications described in the medical records. DIC was defined as a disease state associated with abnormal prothrombin time $(\geq$ $3 \mathrm{~s}$ higher than the reference value) or thrombocytopenia (platelet count $<100 \times 10^{3} / \mathrm{mm}^{3}$ ) during the perioperative period, or clinically evident impaired coagulation in the medical records.

\section{Changes in complete blood count, blood coagulation vari-} ables, and blood chemistry variables

We assessed the complete blood count (CBC; hemoglobin and platelet counts), coagulation variables (activated partial thromboplastin time [APTT], prothrombin time [PT], and international normalized ratio [INR]), and blood chemistry variables (glucose, blood urea nitrogen [BUN], and serum creatinine [Cr]) preoperatively, postoperatively (within 2 days after the end of surgery), and before discharge.

\section{Analysis}

All statistical analyses were performed using IBM SPSS Statistics for Windows (version 26.0; IBM Corp., Armonk, NY, USA). All data are presented as the mean ( $95 \%$ confidence interval) or number (percentage) of patients.

The primary endpoint was the mortality rate, and the secondary endpoints were the frequency of BCS application, perioperative morbidity, and changes in hematologic variables.

Continuous variables were analyzed using the t-test, and nominal variables were analyzed using the $\chi^{2}$ test or Fisher's exact test, as appropriate. For the analysis of time interval data that passed Mauchly's sphericity test, we used repeated-measures analysis of variance (ANOVA). For data that did not pass Mauchly's sphericity test, we used Wilk's lambda multivariate ANOVA. To compare the groups in a given time interval, the $\chi^{2}$ test was used. Statistical significance was set at $\mathrm{p}<0.05$.

\section{RESULTS}

We enrolled a total of 421 patients (59 JW patients and 362 non-JW patients) after reviewing their electronic medical records (Fig. 1). We excluded 120 from 179 patients in the JW group who underwent surgery without a risk of bleeding ( $\mathrm{n}=117)$ and had ASA-PS IV and V $(n=3)$. We likewise excluded 68 from 430 patients in the non-JW group who underwent surgery without a risk of bleeding $(n=49)$ and had ASA-PS IV and V (n=19).

\section{Demographic data}

Significant differences in age, height, weight, and BMI were not observed, except for a higher number of female patients in the JW group (84.7\%) than in the non-JW group (62.4\%) (Table 1). The JW group underwent emergent surgeries more frequently (35.6\%) than the non-JW group (10.5\%) $(\mathrm{p}<0.001$, Table 1$)$. The ASA-PS classification significantly differed between the groups $(\mathrm{p}<0.001$, Table 1$)$. The proportion of patients with ASA-PS I was higher in the JW group (35.6\%) than in the non-JW group (14.9\%), whereas the pro- 
Table 1. Demographic data $(n=421)$

\begin{tabular}{lccc} 
& $\begin{array}{c}\text { JW group } \\
(\mathrm{n}=59)\end{array}$ & $\begin{array}{c}\text { Non-JW group } \\
(\mathrm{n}=362)\end{array}$ & $\mathrm{p}$-value \\
\hline Age $(\mathrm{y})$ & 62.8 & 65 & 0.317 \\
& $(58.0,67.6)$ & $(63.4,66.5)$ & \\
Female sex & 50 & 226 & $0.001^{*}$ \\
& $(84.7)$ & $(62.4)$ & \\
Weight $(\mathrm{kg})$ & 60.5 & 63.4 & 0.230 \\
& $(57.8,63.1)$ & $(61.5,65.3)$ & \\
Height $(\mathrm{cm})$ & 156.7 & 157.6 & 0.688 \\
& $(154.3,159.1)$ & $(155.9,159.4)$ & \\
BMI (kg/m²) & 24.6 & 33.82 & 0.331 \\
& $(23.68,25.52)$ & $(26.32,41.33)$ & \\
ASA-PS ( I / II / III) & $21 / 33 / 5$ & $54 / 206 / 102$ & $<0.001^{*}$ \\
& $(35.6 / 55.9 / 8.5)$ & $(14.9 / 56.9 / 28.2)$ & \\
Emergency (no/yes) & $38 / 21$ & $324 / 38$ & $<0.001^{*}$ \\
& $(64.4 / 35.6)$ & $(89.5 / 10.5)$ & \\
\hline
\end{tabular}

Values are expressed as mean (95\% confidence interval) or number (percentage) of patients.

JW: Jehovah's Witness, BMI: body mass index, ASA-PS: American Society of Anesthesiologists physical status.

${ }^{*} \mathrm{p}<0.05$ was considered to indicate statistical significance.

Table 2. Classification of surgeries $(n=421)$

\begin{tabular}{lccl}
\hline & $\begin{array}{c}\text { JW group } \\
(\mathrm{n}=59)\end{array}$ & $\begin{array}{c}\text { Non-JW group } \\
(\mathrm{n}=362)\end{array}$ & $\mathrm{p}$-value \\
\hline Open abdominal surgery & $5(8.5)$ & $50(13.8)$ & $<0.001^{*}$ \\
Open gynecologic surgery & $15(25.4)$ & $55(15.2)$ & \\
Open hip surgery & $5(8.5)$ & $118(32.6)$ & \\
Open knee surgery & $14(23.7)$ & $50(13.8)$ & \\
Spinal surgery, 1 level & $10(16.9)$ & $22(6.1)$ & \\
Spinal surgery, 2 levels & $6(10.2)$ & $16(4.4)$ & \\
Spinal surgery, >3 levels & $4(6.8)$ & $51(14.1)$ & \\
\hline
\end{tabular}

Values are expressed as number (percentage) of patients. JW: Jehovah's Witness.

${ }^{*} p<0.05$ was considered to indicate statistical significance.

portion of those with ASA-PS III was higher in the non-JW group (28.2\%) than in the JW group (8.5\%) (Table 1).

The various surgeries performed showed significant differences between groups ( $\mathrm{p}<0.001$, Table 2$)$. In the JW group, spinal surgery was the most common surgery performed, followed by open gynecologic surgery, open knee surgery, open hip surgery, and open abdominal surgery. In the non-JW group, open hip surgery was the most common surgery performed, followed by spinal surgery, open gynecologic surgery, open knee surgery, and open abdominal surgery.

The duration of anesthesia was shorter in the JW group
Table 3. Perioperative blood loss, fluid infusion, and transfusion $(n=421)$

\begin{tabular}{|c|c|c|c|}
\hline & $\begin{array}{l}\text { JW group } \\
(n=59)\end{array}$ & $\begin{array}{l}\text { Non-JW group } \\
\quad(n=362)\end{array}$ & $\mathrm{p}$-value \\
\hline Anesthesia duration (h) & $\begin{array}{c}154.6 \\
(133.8,175.4)\end{array}$ & $\begin{array}{c}216.8 \\
(201.9,231.8)\end{array}$ & $<0.001^{*}$ \\
\hline Total blood loss (mL) & $\begin{array}{c}337 \\
(229.3,444.7)\end{array}$ & $\begin{array}{c}1,557.7 \\
(1,343.6,771.8)\end{array}$ & $<0.001^{*}$ \\
\hline Intraoperative & $\begin{array}{c}134 \\
(73.7,194.3)\end{array}$ & $\begin{array}{c}667 \\
(572.9,761.1)\end{array}$ & $<0.001^{*}$ \\
\hline Postoperative & $\begin{array}{c}203 \\
(111.6,294.5)\end{array}$ & $\begin{array}{c}893.4 \\
(716.2,1,070.6)\end{array}$ & $<0.001^{*}$ \\
\hline \multicolumn{4}{|l|}{ Perioperative fluid infusion } \\
\hline $\begin{array}{l}\text { Intraoperative } \\
\text { crystalloid }(\mathrm{mL})\end{array}$ & $\begin{array}{c}897.5 \\
(769.3,1,025.6)\end{array}$ & $\begin{array}{c}1,841.1 \\
(1,702.2,1,980.1)\end{array}$ & $<0.001^{*}$ \\
\hline $\begin{array}{l}\text { Postoperative } \\
\text { crystalloid (mL) }\end{array}$ & $\begin{array}{c}1,764.1 \\
(852.4,2,675.8)\end{array}$ & $\begin{array}{c}9,622.9 \\
(7,533.2,11,712.6)\end{array}$ & 0.647 \\
\hline Colloid infusion (yes) & $10(16.9)$ & $127(35.1)$ & $0.006^{*}$ \\
\hline \multicolumn{4}{|l|}{ Perioperative transfusion } \\
\hline Overall (yes) & $9(15.3)$ & 269 (74.3) & $<0.001^{*}$ \\
\hline $\begin{array}{l}\text { Packed red blood } \\
\text { cells (yes) }\end{array}$ & $0(0)$ & $256(70.7)$ & $<0.001^{*}$ \\
\hline Platelets (yes) & $0(0)$ & $52(14.4)$ & $<0.001^{*}$ \\
\hline $\begin{array}{l}\text { Fresh frozen plasma } \\
\text { (yes) }\end{array}$ & $0(0)$ & $95(26.2)$ & $<0.001^{*}$ \\
\hline Albumin (yes) & $4(6.8)$ & $83(22.9)$ & $0.003^{*}$ \\
\hline Cryoprecipitate (yes) & $0(0)$ & $104(10.2)$ & $0.005^{*}$ \\
\hline Cell salvage (yes) & $6(10.2)$ & $31(8.6)$ & 0.686 \\
\hline
\end{tabular}

Values are expressed as mean (95\% confidence interval) or number (percentage) of patients.

JW: Jehovah's Witness.

${ }^{*} p<0.05$ was considered to indicate statistical significance.

than in the non-JW group $(\mathrm{p}<0.001$, Table 3). Perioperative (intraoperative and postoperative) blood loss was lower in the JW group than in the non-JW group $(\mathrm{p}<0.001$, Table 3$)$. The infused crystalloid volume intraoperatively was lower in the JW group than in the non-JW group $(\mathrm{p}<0.001$, Table 3). The frequency of perioperative colloid infusion was also lower in the JW group (16.9\%) than in the non-JW group (35.1\%) ( $\mathrm{p}=0.006$, Table 3).

The overall rate of perioperative transfusion was significantly different between the JW (15.3\%) and the non-JW (74.3\%) groups ( $\mathrm{p}<0.001$, Table 3$)$. The JW group did not receive any packed red blood cells, platelets, fresh frozen plasma, or cryoprecipitate. Albumin was administered to 4 (6.8\%) patients in the JW group and 83 (22.9\%) patients in the nonJW group ( $\mathrm{p}=0.003)$. Autologous blood transfusion after cell salvage was administered to $6(10.2 \%)$ patients in the JW group and $31(8.6 \%)$ patients in the non-JW group ( $\mathrm{p}=0.686)$. 
Mortality, morbidity, and other complications

The mortality rate in the JW group was $0 \%$, which was lower than that in the non-JW group (3\%), but was not statistically significant ( $\mathrm{p}=0.370$, Table 4). Massive bleeding occurred in $3.4 \%$ and $11.8 \%$ of patients in the JW and the non-JW groups, respectively, but the difference was also not statistically significant $(\mathrm{p}=0.064$, Table 4$)$. There were no postoperative infections in the JW group, compared to $8.4 \%$ in the non-JW group ( $\mathrm{p}=0.013$, Table 4). Early discontinuation of surgery was not done in the JW group but occurred

Table 4. Incidences of death, infection and disseminated intravascular coagulation $(n=421)$

\begin{tabular}{lccc}
\hline & $\begin{array}{c}\text { JW group } \\
(\mathrm{n}=59)\end{array}$ & $\begin{array}{c}\text { Non-JW group } \\
(\mathrm{n}=362)\end{array}$ & $\mathrm{p}$-value \\
\hline Death & $0(0)$ & $10(3)$ & 0.370 \\
Infection & $0(0)$ & $29(8.4)$ & $0.013^{*}$ \\
DIC & $2(3.4)$ & $58(16)$ & $0.008^{*}$ \\
Hospital stay (d) & $15.3(12.7,18)$ & $22.5(20.3,24.7)$ & $<0.001^{*}$ \\
\hline
\end{tabular}

Values are expressed as number (percentage) of patients. JW: Jehovah's Witness, DIC: disseminated intravascular coagulation. ${ }^{*} p<0.05$ was considered to indicate statistical significance.

Table 5. Perioperative complete blood count (hemoglobin and platelet counts) $(n=421)$

\begin{tabular}{lccc}
\hline & $\begin{array}{c}\text { JW group } \\
(\mathrm{n}=59)\end{array}$ & $\begin{array}{c}\text { Non-JW group } \\
(\mathrm{n}=362)\end{array}$ & $\mathrm{p}$-value \\
\hline $\mathrm{Hb}(\mathrm{g} / \mathrm{dL})$ & & & 0.075 \\
Preoperative & $12.1(11.7,12.4)$ & $11.5(11.2,11.7)$ & $0.003^{*}$ \\
Postoperative & $11(10.6,11.3)$ & $9.8(9.6,10.0)$ & $<0.001^{*}$ \\
Discharge & $10.5(10.1,10.9)$ & $9.8(9.6,10.0)$ & $0.006^{*}$ \\
$\mathrm{Hb}(<10 \mathrm{~g} / \mathrm{dL})$ & & & \\
Preoperative & $3(5.1)$ & $89(24.6)$ & $0.001^{*}$ \\
Postoperative & $15(25.4)$ & $205(56.6)$ & $<0.001^{*}$ \\
Discharge & $25(42.4)$ & $224(61.9)$ & $0.005^{*}$ \\
Platelets $\left(\times 10^{3} / \mathrm{mm}^{3}\right)$ & & & $0.018^{*}$ \\
Preoperative & 266.2 & 267.3 & 0.918 \\
& $(246.3,286)$ & $(255.9,278.8)$ & \\
Postoperative & 254.8 & 228.3 & $0.028^{*}$ \\
& $(233.6,276.1)$ & $(218.1,238.5)$ & \\
Discharge & 343.7 & 320.7 & 0.233 \\
& $(299.1,388.3)$ & $(307.2,334.2)$ & \\
Platelets $\left(<15 \times 10^{3} / \mathrm{mm}^{3}\right)$ & & & \\
Preoperative & $3(5.1)$ & $43(11.9)$ & 0.121 \\
Postoperative & $3(5.1)$ & $74(20.4)$ & $0.005^{*}$ \\
Discharge & $1(1.7)$ & $30(8.3)$ & 0.102 \\
\hline
\end{tabular}

Values are expressed as mean (95\% confidence interval) or number (percentage) of patients.

JW: Jehovah's Witness, $\mathrm{Hb}$ : hemoglobin.

${ }^{*} p<0.05$ was considered to indicate statistical significance. in $0.9 \%$ of patients in the non-JW group ( $\mathrm{p}=1.000$, Table 4 ). The incidence of DIC was higher in the non-JW group (16\%) than in the JW group (3.4\%) ( $\mathrm{p}=0.008$, Table 4). Hospital stay was shorter in the JW group than in the non-JW group ( $<<0.001$, Table 4).

\section{Changes in $\mathrm{CBC}$, blood coagulation variables, and blood chemistry variables \\ Changes in CBC}

The perioperative hemoglobin level was not significantly different between the groups ( $\mathrm{p}=0.075$, Table 5). However, the hemoglobin level at each time point was higher in the JW group than in the non-JW group ( $\mathrm{p} \leq 0.006$, Table 5$)$. The incidence of hemoglobin levels $<10 \mathrm{~g} / \mathrm{dL}$ was lower in the JW group than in the non-JW group throughout the perioperative period ( $\mathrm{p} \leq 0.005$, Table 5).

The perioperative platelet count was significantly different between the groups ( $p=0.018$, Table 5$)$. The postoperative platelet count was higher in the JW group than in the nonJW group ( $\mathrm{p}=0.028$, Table 5$)$, whereas the preoperative and discharge platelet counts were not significantly different between the groups. The incidence of postoperative platelet count $<150 \times 10^{3} / \mathrm{mm}^{3}$ was lower in the JW group (5.1\%) than in the non-JW group (20.4\%, $\mathrm{p}=0.005)$; however, the incidence of low platelet count before surgery and at discharge was not significantly different (Table 5).

\section{Changes in blood coagulation variables}

Perioperative APTT, PT, and INR were higher in the nonJW group than in the JW group ( $\mathrm{p}<0.001$, Table 6), although preoperatively, there was no significant difference between the groups in these variables. The incidences of prolonged PT ( $\geq 12.6 \mathrm{~s}$ ) and elevated INR ( $\geq 1.28$ ) were higher in the non-JW group than in the JW group at the end of surgery $(p<0.001)$ and before discharge $(p<0.001$, Table 6). However, the incidence of prolonged APTT ( $\geq 45 \mathrm{~s}$ ) was not significantly different between the groups throughout the perioperative period.

\section{Changes in blood chemistry variables}

Perioperative blood chemistry variables were not significantly different between the groups (Table 7). At each measurement point, the perioperative blood glucose, BUN, and $\mathrm{Cr}$ levels also did not show significant differences between 
Table 6. Perioperative coagulation variables $(n=421)$

\begin{tabular}{|c|c|c|c|}
\hline & $\begin{array}{l}\text { JW group } \\
(n=59)\end{array}$ & $\begin{array}{l}\text { Non-JW group } \\
\quad(n=362)\end{array}$ & $\mathrm{p}$-value \\
\hline APTT (s) & & & $0.002^{*}$ \\
\hline Preoperative & $29.6(28.5,30.6)$ & $30.0(29.5,30.5)$ & 0.500 \\
\hline Postoperative & $27.4(27.0,27.7)$ & $29.3(28.9,29.8)$ & $<0.001^{*}$ \\
\hline Discharge & $29.0(28.1,30.0)$ & $32.8(32.1,33.5)$ & $<0.001^{*}$ \\
\hline \multicolumn{4}{|l|}{ APTा ( $\geq 45 \mathrm{~s})$} \\
\hline Preoperative & $0(0)$ & $5(1.4)$ & 1.000 \\
\hline Postoperative & $0(0)$ & $6(1.7)$ & 1.000 \\
\hline Discharge & $0(0)$ & $11(3)$ & 0.376 \\
\hline $\mathrm{PT}(\mathrm{s})$ & & & $0.008^{*}$ \\
\hline Preoperative & $11.1(10.5,11.7)$ & $11.5(11.3,11.8)$ & 0.181 \\
\hline Postoperative & $11.7(11.6,11.8)$ & $13.2(12.9,13.4)$ & $<0.001^{*}$ \\
\hline Discharge & $12.5(12.4,12.7)$ & $14.1(13.7,14.4)$ & $<0.001^{*}$ \\
\hline \multicolumn{4}{|l|}{$\mathrm{PT}(\geq 12.6 \mathrm{~s})$} \\
\hline Preoperative & $4(6.8)$ & 49 (13.5) & 0.147 \\
\hline Postoperative & $3(5.1)$ & $245(67.7)$ & $<0.001^{*}$ \\
\hline Discharge & $3(5.1)$ & 300 (82.9) & $<0.001^{*}$ \\
\hline INR & & & 0.672 \\
\hline Preoperative & $1.0(0.9,1.0)$ & $1.1(1.0,1.1)$ & 0.141 \\
\hline Postoperative & $1.0(1.0,1.0)$ & $1.2(1.2,1.2)$ & $<0.001^{*}$ \\
\hline Discharge & $1.1(1.1,1.1)$ & $1.3(1.2,1.3)$ & $<0.001^{*}$ \\
\hline \multicolumn{4}{|l|}{ INR ( $(\geq 1.28)$} \\
\hline Preoperative & $2(3.4)$ & $25(6.9)$ & 0.402 \\
\hline Postoperative & $1(1.7)$ & 41 (11.3) & $0.018^{*}$ \\
\hline Discharge & $1(1.7)$ & 232 (64.1) & $<0.001^{*}$ \\
\hline
\end{tabular}

Values are expressed as mean (95\% confidence interval) or number (percentage) of patients.

JW: Jehovah's Witness, APTT: activated partial thromboplastin time, PT: prothrombin time, INR: international normalized ratio.

${ }^{*} \mathrm{p}<0.05$ was considered to indicate statistical significance.

the groups, except for the higher preoperative glucose level in the non-JW group than in the JW group (Table 7).

The incidences of perioperatively elevated blood glucose, BUN, and Cr levels were not significantly different, although there was a higher proportion of patients with abnormal postoperative glucose levels at the end of surgery in the JW group (78\%) than in the non-JW group (61.9\%) (p=0.017, Table 7).

\section{Perioperative BCS}

Iron preparations and other systemic hemostatics were more frequently used in the JW group than in the non-JW group ( $\mathrm{p}<0.001$, Table 8 ); however, antifibrinolytics were less frequently used in the JW group ( $\mathrm{p}=0.007$, Table 8$)$. The use of cell salvage was not significantly different between the
Table 7. Perioperative blood chemistry variables $(n=421)$

\begin{tabular}{|c|c|c|c|}
\hline & $\begin{array}{l}\text { JW group } \\
(n=59)\end{array}$ & $\begin{array}{l}\text { Non-JW group } \\
\quad(n=362)\end{array}$ & $\mathrm{p}$-value \\
\hline Glucose (mg/dL) & & & 0.246 \\
\hline Preoperative & $\begin{array}{c}108.6 \\
(100.8,116.4)\end{array}$ & $\begin{array}{c}121.3 \\
(116.1,126.4)\end{array}$ & $0.008^{*}$ \\
\hline Postoperative & $\begin{array}{c}130.6 \\
(121.9,139.3)\end{array}$ & $\begin{array}{c}131.9 \\
(126.2,137.5)\end{array}$ & 0.866 \\
\hline Discharge & $\begin{array}{c}104.2 \\
(95.8,112.5)\end{array}$ & $\begin{array}{c}106.4 \\
(102.5,110.2)\end{array}$ & 0.665 \\
\hline \multicolumn{4}{|c|}{ Glucose ( $\geq 110 \mathrm{mg} / \mathrm{dL})$} \\
\hline Preoperative & $24(40.7)$ & $174(48.1)$ & 0.292 \\
\hline Postoperative & $46(78)$ & $224(61.9)$ & $0.017^{*}$ \\
\hline Discharge & $17(28.8)$ & $106(29.3)$ & 0.942 \\
\hline BUN (mg/dL) & & & 0.751 \\
\hline Preoperative & $14.6(13.1,16.1)$ & $16.6(15.5,17.6)$ & 0.134 \\
\hline Postoperative & $15.0(13.0,17.0)$ & $16.8(15.7,18.0)$ & 0.216 \\
\hline Discharge & $15.7(13.8,17.7)$ & $16.6(15.4,17.9)$ & 0.575 \\
\hline \multicolumn{4}{|l|}{ BUN ( $\geq 21 \mathrm{mg} / \mathrm{dL})$} \\
\hline Preoperative & $9(15.3)$ & 77 (21.3) & 0.288 \\
\hline Postoperative & $12(20.3)$ & $89(24.6)$ & 0.479 \\
\hline Discharge & $11(18.6)$ & $76(21)$ & 0.679 \\
\hline $\mathrm{Cr}(\mathrm{mg} / \mathrm{dL})$ & & & 0.543 \\
\hline Preoperative & $0.9(0.7,1.1)$ & $0.9(0.9,1.0)$ & 0.786 \\
\hline Postoperative & $1.0(0.8,1.2)$ & $0.9(0.9,1.0)$ & 0.833 \\
\hline Discharge & $0.9(0.8,1.1)$ & $1.0(0.9,1.1)$ & 0.739 \\
\hline \multicolumn{4}{|l|}{$\mathrm{Cr}(\geq 1.4 \mathrm{mg} / \mathrm{dL})$} \\
\hline Preoperative & $7(11.9)$ & $33(9.1)$ & 0.504 \\
\hline Postoperative & $5(8.5)$ & $35(9.7)$ & 0.772 \\
\hline Discharge & $5(8.5)$ & $50(13.8)$ & 0.259 \\
\hline
\end{tabular}

Values are expressed as mean (95\% confidence interval) or number (percentage) of patients.

JW: Jehovah's Witness, BUN: blood urea nitrogen, Cr: serum creatinine. ${ }^{*} \mathrm{p}<0.05$ was considered to indicate statistical significance.

groups (Table 8). None of the patients received other BCSs, such as administration of erythropoietin and prothrombin complex concentrate.

The anesthesia methods did not show significant differences between the groups ( $\mathrm{p}=0.709$, Table 8 ). In the JW group, balanced anesthesia was the preferred method, followed by total intravenous anesthesia, inhaled anesthesia, and neuroaxial anesthesia. In the non-JW group, balanced anesthesia was also the preferred method, followed by inhaled anesthesia, total intravenous anesthesia, and neuroaxial anesthesia.

The incidences of intraoperative and postoperative hypothermia were significantly different between the groups ( $\mathrm{p}=0.013$ and $\mathrm{p}=0.003$, respectively; Table 8 ). All JW patients 
Table 8. Perioperative blood conservation strategies $(n=421)$

\begin{tabular}{|c|c|c|c|}
\hline & $\begin{array}{l}\text { JW group } \\
(n=59)\end{array}$ & $\begin{array}{c}\text { Non-JW group } \\
\quad(n=362)\end{array}$ & $\mathrm{p}$-value \\
\hline Antifibrinolytics (yes) & $6(10.2)$ & 95 (26.2) & $0.007^{*}$ \\
\hline Iron preparations (yes) & $9(15.3)$ & $12(3.3)$ & $<0.001^{*}$ \\
\hline $\begin{array}{l}\text { Other systemic hemostatics } \\
\text { (yes) }\end{array}$ & $22(37.3)$ & $47(13)$ & $<0.001^{*}$ \\
\hline Cell salvage (yes) & $6(10.2)$ & $31(8.6)$ & 0.686 \\
\hline \multicolumn{4}{|l|}{ Anesthesia methods } \\
\hline Inhaled anesthesia & $10(16.9)$ & $71(19.7)$ & 0.709 \\
\hline Balanced anesthesia & 31 (52.5) & $179(49.6)$ & \\
\hline $\begin{array}{l}\text { Total intravenous } \\
\text { anesthesia }\end{array}$ & $11(18.6)$ & $53(14.7)$ & \\
\hline Neuroaxial anesthesia & $7(11.9)$ & $58(16.1)$ & \\
\hline \multicolumn{4}{|l|}{ Control of body temperature } \\
\hline \multicolumn{4}{|c|}{ Incidence $\left(\geq 36.0^{\circ} \mathrm{C} /<36.0^{\circ} \mathrm{C}\right)$} \\
\hline Intraoperative & $\begin{array}{c}0 / 59 \\
(0 / 100)\end{array}$ & $\begin{array}{c}31 / 331 \\
(8.6 / 91.4)\end{array}$ & $0.013^{*}$ \\
\hline Postoperative & $\begin{array}{c}0 / 59 \\
(0 / 100)\end{array}$ & $\begin{array}{l}40 / 322 \\
(11 / 89)\end{array}$ & $0.003^{*}$ \\
\hline \multicolumn{4}{|l|}{ Prevention methods (yes/no) } \\
\hline Overall & $\begin{array}{l}23 / 36 \\
(39 / 61)\end{array}$ & $\begin{array}{c}243 / 119 \\
(67.1 / 32.9)\end{array}$ & $<0.001^{*}$ \\
\hline Forced-air warming & $\begin{array}{c}23 / 36 \\
(39 / 61)\end{array}$ & $\begin{array}{c}236 / 93 \\
(71.7 / 28.3)\end{array}$ & $<0.001^{*}$ \\
\hline IV fluid warming & $\begin{array}{c}3 / 56 \\
(5.1 / 94.9)\end{array}$ & $\begin{array}{c}61 / 246 \\
(19.9 / 80.1)\end{array}$ & $0.006^{*}$ \\
\hline Passive warming & $\begin{array}{c}2 / 57 \\
(3.4 / 96.6)\end{array}$ & $\begin{array}{c}23 / 281 \\
(7.6 / 92.4)\end{array}$ & 0.398 \\
\hline
\end{tabular}

Values are expressed as numbers (percentages) of patients.

JW: Jehovah's Witness, IV: intravenous, Passive warming: warming of patients with a warm blanket.

${ }^{*} p<0.05$ was considered to indicate statistical significance.

experienced mild hypothermia $\left(35.5^{\circ} \mathrm{C}<\right.$ temperature $\leq$ $36.0^{\circ} \mathrm{C}$ ), whereas normal body temperature and mild hypothermia were observed in $10 \%$ and $90 \%$ of patients receiving blood transfusion, respectively.

Protocols for preventing hypothermia, which include forced-air warming $(\mathrm{p}<0.001)$ and intravenous fluid warming $(p=0.006)$, were more frequently applied in the non-JW group than in the JW group $(\mathrm{p}<0.001$, Table 8$)$.

\section{DISCUSSION}

This study is meaningful in that it analyzed the outcomes of perioperative management of Korean JW patients undergoing bloodless surgeries. The results of this study showed that most JW patients safely underwent surgery without blood transfusions and without developing significant he- matologic abnormalities, compared to patients who received blood transfusion under standard transfusion protocols.

\section{Mortality, morbidity, and other complications}

Preoperative correction of anemia is essential, as decreased preoperative hemoglobin levels are associated with increased morbidity and mortality [15]. Therefore, allogeneic blood and blood derivatives are usually transfused to compensate for significant intraoperative blood loss. However, allogeneic blood transfusion can lead to perioperative coagulopathy or even DIC, which can result in postoperative bleeding, renal failure, increased risk of infection, prolonged hospital stay, and increased postoperative morbidity and mortality, independent of patient comorbidities and preoperative hemoglobin levels [16-18].

JW patients who received perioperative BCSs showed similar or better outcomes compared to patients who received blood transfusion [19-22]. In open knee surgeries, the postoperative complication rate was not significantly different between the JW (3.9\%) and non-JW (3.2\%) groups [20]. In JW patients who underwent bloodless emergency laparotomy with hemorrhagic shock, mortality was lower in the JW group (12\%) than in the group that received blood transfusion (15.6\%) [21]. They also showed that the infectious mortality rate was lower (30\% vs. $40 \%$ ) and the DIC incidence was lower $(0.0 \%$ vs. $4.4 \%)$ in JW patients than in patients who received allogeneic blood transfusion [21]. In the study by Kim et al. [22], the perioperative $\mathrm{Cr}$ level, as an indicator of renal injury, was not significantly different between the groups.

Postoperative anemia-related mortality was relatively uncommon in JW patients, and overall mortality was lower in patients who refused (0\%) than in those who received blood transfusion (3.6\%) [19,20,23]. Frank et al. [19] reported that the mortality rate was not significantly different between groups, although the incidence of hemoglobin nadir $<5 \mathrm{~g} /$ $\mathrm{dL}$ was higher in JW patients (4.3\%) than in patients who received blood transfusion (0.2\%). The hemoglobin levels of JW patients who received BCSs did not significantly differ from those of non-JW patients at $1 \mathrm{~d}$ postoperatively [20]. De Bellis et al. [24] reported that the lowest hemoglobin level was $7.1 \mathrm{~g} / \mathrm{dL}$ with a median decrement of $2.8 \mathrm{~g} / \mathrm{dL}$ (range 0-6.9 g/dL), and no patient required blood transfusion or died within 3 months after surgery among JW patients who 
underwent major abdominal surgeries. Furthermore, propensity-matched studies showed lower morbidity and mortality rates in patients who underwent bloodless surgeries $[19,25]$. However, it should be considered that postoperative hemoglobin $<5.0 \mathrm{~g} / \mathrm{dL}$ has been shown to increase mortality in JW patients [12,26] and specific surgeries with risks of catastrophic hemorrhage also increase the mortality risk in patients undergoing bloodless surgeries [27].

This study showed decreased perioperative blood loss and lower incidences of postoperative infection, coagulopathy, and DIC in the JW group than in the non-JW group, whereas mortality, massive bleeding, and renal insufficiency were not significantly different between the groups. It was assumed that the non-JW group liberally received perioperative allogeneic transfusion and fluid administration, causing abnormal coagulation profiles and increased postoperative bleeding, eventually increasing the risk for postoperative infection, DIC, and prolonged hospital stay.

\section{Perioperative BCS}

Various perioperative BCSs can be used to minimize blood loss, optimize anemia tolerance, enhance hemoglobin and red blood cell production, correct coagulation defects, and promote hemostasis. These BCSs include the administration of erythropoietin, prothrombin complex concentrate, oral or intravenous iron preparations, and antifibrinolytics; preoperative autologous donation; acute normovolemic hemodilution; autologous blood transfusion after cell salvage; and use of various anesthetic techniques, such as intraoperative induction of mild hypothermia and application of permissive hypotension [14-16,28-30]. Many studies have shown that patients who refuse blood transfusion, such as JWs, can safely undergo surgery with the application of aggressive BCSs [16,31-33].

The present study also showed that BCSs were more frequently applied in JW patients (61\%), who were able to undergo surgery without allogeneic blood transfusion in a safer manner than patients who received blood transfusion (48.3\%). In addition, the perioperative application of BCSs was effective in achieving hemoglobin nadirs and outcomes in JW patients similar to those in patients who received transfusion [16].

\section{Perioperative management with medicine}

This study showed that hemocoagulase, which is classified as a group of other systemic hemostatics, was the most commonly applied BCS (37.3\%) in JW patients, followed by iron preparations (15.3\%), antifibrinolytics (10.2\%), and cell salvage (10.2\%). In contrast, in non-JW patients, antifibrinolytics (26.2\%) were the most commonly applied BCS. At our hospital, we could not use erythropoietin because of the constraints of health insurance schemes. Therefore, we preferred using antifibrinolytics, oral or intravenous iron preparations, and other systemic hemostatics. Although erythropoietin is an effective alternative to blood transfusion, it has another limitation of taking a long time ( 4 weeks) to promote sufficient erythropoiesis (3 days for erythropoiesis, 7 days for 1 unit of blood, and 28 days for 5 units of blood) [33]. Therefore, erythropoietin may be ineffective in overcoming perioperative blood loss if not administered early enough.

\section{Anesthetic techniques}

Permissive or induced hypotension (systolic blood pressure of 80-90 mmHg, mean arterial pressure of 50-65 $\mathrm{mmHg}$, or a $30 \%$ reduction in the mean arterial pressure at baseline) can reduce perioperative blood loss in JW patients [4,34,35]. Effective permissive hypotension can be achieved using pharmacological agents alone or in combination with inhaled anesthetics, sodium nitroprusside, nitroglycerin, remifentanil, calcium channel blockers, $\beta$-blockers, and agents used in neuroaxial anesthesia [36]. Balanced anesthesia, total intravenous anesthesia, and neuroaxial anesthesia are preferable anesthetic methods in JW patients, considering the lower toxicity, safer recovery, and natural hypotensive effect of the anesthetic drugs [36,37]. Nwosu [37] documented that anesthesia with permissive hypotension was useful in reducing surgical blood loss and improving surgical site visibility while reducing the surgical time in selected cases, such as in patients undergoing spinal surgery or total hip surgery [16,31]. This study also showed that general anesthesia with opioids and neuroaxial anesthesia was preferred, although we did not investigate whether permissive hypotension was performed.

Induction of mild to moderate hypothermia has also been successfully used as a BCS; however, hypothermia below $35^{\circ} \mathrm{C}$ should be avoided to prevent coagulopathy and blood loss [14]. Mild intraoperative hypothermia (between 
$35.5^{\circ} \mathrm{C}$ and $36.0^{\circ} \mathrm{C}$ ) was observed in all JW patients and in $91.4 \%$ of non-JW patients in this study.

\section{Transfusions}

Although JWs refuse allogeneic blood transfusion, some may allow the prevention or control of perioperative anemia with acute normovolemic hemodilution or blood cell salvage, based on personal decision [1-4,30]. However, we could not perform acute normovolemic hemodilution because of the policy restrictions of blood banks and technical difficulties in our hospital. Therefore, we only applied perioperative autologous blood cell salvage to minimize the need for allogeneic transfusion as an alternative technique. Although not routinely performed, the use of blood that remains in continuity with the patient's circulation can be safely accepted by JWs on a per-patient basis [38-40]. If possible, blood salvage is recommended as a backup measure in patients undergoing surgeries with a risk of moderate or low blood loss [19]. Blood salvage was applied in $10.2 \%$ of JW patients and $8.6 \%$ of non-JW patients in this study.

\section{Surgical techniques}

When performing complex and lengthy surgeries in JW patients, surgeons should consider staged operations or techniques that can reduce the risk of perioperative bleeding and transfusion $[14,15]$. The JW patients enrolled in this study underwent less complex surgeries with a short expected operative time, and none of them required a staged operation.

\section{Study limitations}

This study has several limitations, warranting cautious interpretation of our findings. First, the retrospective analysis may have influenced the results of this study. Second, the single-center design and the small sample size of the JW group limit the generalization of our results. Third, we included many different types of surgeries, which may have resulted in unfair comparisons. Finally, we did not perform propensity matching to control for various biases. As a result of the uncontrolled biases, various types of surgeries were included in the analysis of this study at different frequencies between the groups, which may have resulted in significant differences in anesthetic duration, perioperative fluid infusion amounts, and incidence of perioperative hypothermia and DIC.

In conclusions, most JW patients can safely undergo surgeries that have a risk of bleeding without blood transfusions, similar to patients who are given blood transfusion. This was achieved through physicians' efforts to reduce or prevent perioperative bleeding by applying various perioperative BCSs. Despite the limitations of our retrospective study and the need for further studies to confirm our results and conclusions, the present findings are useful in that they support existing findings and contribute to updating the information on the perioperative outcomes of JW patients. In addition, this study adds to the evidence that perioperative blood transfusion is associated with increased mortality and morbidity after surgery.

\section{ACKNOWLEDGEMENTS}

This study was supported by a research fund from Chosun University Hospital (Donggu, Gwangju, Republic of Korea), 2019. The Chosun University Hospital had no role in the design or conduct of the study; collection, management, analysis, or interpretation of the data; and preparation, review, or approval of the manuscript.

\section{CONFLICT OF INTEREST}

No potential conflict of interest relevant to this article was reported.

\section{REFERENCES}

1. Questions from readers. Brooklyn, NY: Watch Tower Bible and Tract Society; 2000. p. 29-31.

2. Mihas A, Ramchandran S, Rivera S, Mansour A, Asghar J, Shufflebarger $\mathrm{H}$, et al. Safe and effective performance of pediatric spinal deformity surgery in patients unwilling to accept blood transfusion: a clinical study and review of literature. BMC Musculoskelet Disord 2021;22:204.

3. Muramoto O. Jehovah's Witnesses and artificial blood. CMAJ 2001;164:969.

4. Brodsky JW, Dickson JH, Erwin WD, Rossi CD. Hypotensive anesthesia for scoliosis surgery in Jehovah's Witnesses. Spine (Phila Pa 1976) 1991;16:304-6.

5. Shander A. Surgery without blood. Crit Care Med 2003;31: S708-14.

6. Resar LM, Frank SM. Bloodless medicine: what to do when 
you can't transfuse. Hematology Am Soc Hematol Educ Program 2014;2014:553-8.

7. Lee SH, Kim DG, Shin HS. How to approach orthognathic surgery in patients who refuse blood transfusion. Arch Plast Surg 2020;47:404-10.

8. Jeong JY, Jee HS, Koo BS, Cho SH, Kim SH, Kim G. Liver transplantation in Jehovah's Witnesses: two cases report. Korean J Anesthesiol 2017;70:350-5.

9. Woo da E, Lee JM, Kim YK, Park YH. Recombinant human erythropoietin therapy for a Jehovah's Witness child with severe anemia due to hemolytic-uremic syndrome. Korean J Pediatr 2016;59:100-3.

10. Suh YS, Nho JH, Choi HS, Ha YC, Park JS, Koo KH. A protocol avoiding allogeneic transfusion in joint arthroplasties. Arch Orthop Trauma Surg 2016;136:1213-26.

11. Jeon YB, Yun S, Choi D. Transfusion free radical antegrade modular pancreaticosplenectomy of metastatic neuroendocrine tumor of the pancreas in Jehovah's Witness patient. Ann Surg Treat Res 2015;88:106-10.

12. Shander A, Javidroozi M, Naqvi S, Aregbeyen O, Caylan M, Demir S, et al. An update on mortality and morbidity in patients with very low postoperative hemoglobin levels who decline blood transfusion (CME). Transfusion 2014;54:268895; quiz 2687.

13. Jones JW, McCullough LB, Richman BW. Painted into a corner: unexpected complications in treating a Jehovah's Witness. J Vasc Surg 2006;44:425-8.

14. Lawson T, Ralph C. Perioperative Jehovah's Witnesses: a review. Br J Anaesth 2015;115:676-87.

15. Rollins KE, Contractor U, Inumerable R, Lobo DN. Major abdominal surgery in Jehovah's Witnesses. Ann R Coll Surg Engl 2016;98:532-7.

16. Kisilevsky AE, Stobart L, Roland K, Flexman AM. Optimization and outcomes of patients who decline blood transfusion during complex spine surgery: a retrospective cohort study. Can J Anaesth 2016;63:1108-9.

17. Seicean A, Alan N, Seicean S, Neuhauser D, Weil RJ. The effect of blood transfusion on short-term, perioperative outcomes in elective spine surgery. J Clin Neurosci 2014;21: 1579-85.

18. Sheth M, Kulkarni S, Dhanireddy K, Perez A, Selby R. Blood conservation strategies and liver transplantation transfusion-free techniques derived from Jehovah's Witness surgical cohorts. Mo Med 2015;112:389-92.

19. Frank SM, Wick EC, Dezern AE, Ness PM, Wasey JO, Pippa AC, et al. Risk-adjusted clinical outcomes in patients enrolled in a bloodless program. Transfusion 2014;54:2668-77.

20. Harwin SF, Issa K, Naziri Q, Johnson AJ, Mont MA. Results of primary total knee arthroplasty in Jehovah's Witness patients. J Arthroplasty 2013;28:49-55.
21. Chigbu B, Onwere S, Kamanu C, Aluka C, Okoro O, Feyi-Waboso $\mathrm{P}$, et al. Lessons learned from the outcome of bloodless emergency laparotomies on Jehovah's Witness women presenting in the extremis with ruptured uterus. Arch Gynecol Obstet 2009;279:469-72.

22. Kim TS, Lee JH, Na CY. Blood conservation strategy during cardiac valve surgery in Jehovah's Witnesses: a comparative study with Non-Jehovah's Witnesses. Korean J Crit Care Med 2016;31:101-10.

23. Viele MK, Weiskopf RB. What can we learn about the need for transfusion from patients who refuse blood? The experience with Jehovah's Witnesses. Transfusion 1994;34:396-401.

24. De Bellis M, Girelli D, Ruzzenente A, Bagante F, Ziello R, Campagnaro T, et al. Pancreatic resections in patients who refuse blood transfusions. The application of a perioperative protocol for a true bloodless surgery. Pancreatology 2020;20:1550-7.

25. Pattakos G, Koch CG, Brizzio ME, Batizy LH, Sabik JF 3rd, Blackstone EH, et al. Outcome of patients who refuse transfusion after cardiac surgery: a natural experiment with severe blood conservation. Arch Intern Med 2012;172:1154-60.

26. Jo KI, Shin JW, Choi TY, Park YJ, Youm W, Kim MJ. Eightyear experience of bloodless surgery at a tertiary care hospital in Korea. Transfusion 2013;53:948-54.

27. Singla AK, Lapinski RH, Berkowitz RL, Saphier CJ. Are women who are Jehovah's Witnesses at risk of maternal death? Am J Obstet Gynecol 2001;185:893-5.

28. Khalili M, Morano WF, Marconcini L, Shaikh MF, Gleeson EM, Styler M, et al. Multidisciplinary strategies in bloodless medicine and surgery for patients undergoing pancreatectomy. J Surg Res 2018;229:208-15.

29. Lee BW, Park MG, Cho DY, Park SS, Yeo JK. Preoperative erythropoietin administration in patients with prostate cancer undergoing radical prostatectomy without transfusion. Korean J Urol 2014;55:102-5.

30. Tse A, Chow O, Matar A, Alzahrani N, Morris D. Strategies for 'bloodless' surgery: the experience of cytoreductive surgery for peritoneal carcinomatosis in Jehovah's Witnesses. ANZ J Surg 2020;90:1953-7.

31. Harwin SF, Pivec R, Naziri Q, Issa K, Mont MA. Is total hip arthroplasty a successful and safe procedure in Jehovah's Witnesses? Mean five-year results. Hip Int 2014;24:69-76.

32. Lim C, Salloum C, Esposito F, Giakoustidis A, Moussallem T, Osseis M, et al. Safety and feasibility of elective liver resection in adult Jehovah's Witnesses: the Henri Mondor Hospital experience. HPB (Oxford) 2018;20:823-8.

33. Trzciński R, Kujawski R, Mik M, Berut M, Dziki 1 , Dziki A. Surgery in Jehovah's Witnesses - our experience. Prz Gastroenterol 2015;10:33-40.

34. Nelson CL, Bowen WS. Total hip arthroplasty in Jehovah's 
Witnesses without blood transfusion. J Bone Joint Surg Am 1986;68:350-3.

35. Boldt J, Weber A, Mailer K, Papsdorf M, Schuster P. Acute normovolaemic haemodilution vs controlled hypotension for reducing the use of allogeneic blood in patients undergoing radical prostatectomy. Br J Anaesth 1999;82:170-4.

36. Degoute CS. Controlled hypotension: a guide to drug choice. Drugs 2007;67:1053-76.

37. Nwosu AD. Multimodal approach to blood conservation in the surgical patient. Niger J Clin Pract 2015;18:422-5.
38. Ashworth A, Klein AA. Cell salvage as part of a blood conservation strategy in anaesthesia. Br J Anaesth 2010;105:401-16.

39. Nagy CJ, Wheeler AS, Archer TL. Acute normovolemic hemodilution, intraoperative cell salvage and PulseCO hemodynamic monitoring in a Jehovah's Witness with placenta percreta. Int J Obstet Anesth 2008;17:159-63.

40. Hughes DB, Ullery BW, Barie PS. The contemporary approach to the care of Jehovah's witnesses. J Trauma 2008;65: 237-47. 